\title{
8-XVIII. Yüzyıla ait Bulgar Katolik metnindeki (Pavlikan) Türkçe unsurlar hakkında bir değerlendirme
}

\section{Abidin KARASU1}

\begin{abstract}
APA: Karasu A. (2020). XVIII. Yüzylla ait Bulgar Katolik metnindeki (Pavlikan) Türkçe unsurlar hakkında bir değerlendirme. RumeliDE Dil ve Edebiyat Araştırmaları Dergisi, (21), 137-150. DOI: $10.29000 /$ rumelide.835523.
\end{abstract}

$\ddot{O} \mathbf{z}$

Bulgaristan Milli Kütüphanesi “Sv. Kiril ve Metodiy”'de bulunan ve Petar Kovachev Tsarski (Petar Fabri Imperiali) tarafından 1773 tarihinde yazılan eser, Bulgar Katolik Edebiyatının (Pavlikan) en eski el yazması metnidir. Yazar, eseri İtalyancadan Bulgarcaya çevirmiş ve Latin harflerini kullanmıştır. İki ana bölümden oluşan eserin birinci bölüm Katolik öğretileri ve dualarından oluşmakta olup ikinci bölümünde İncil hakkında yorumlara yer verilmiştir. Eserin en dikkat çeken yönü, Türkçe unsurların yoğun şekilde kullanılmasıdır. Yalın bir dil kullanan yazar, Bulgar Katolik cemaatine daha yakın hitap etmek için Türkçe sözcüklerden istifade etmiştir. Bu durum, XVIII. Yüzyılda Türkçenin Bulgaristan topraklarındaki varlığını ve işlevselliğini ortaya koymada önemli ipuçları vermektedir. Özellikle el yazmasının ikinci bölümünde Hz. İsa'nın hayatını anlatan yazar bu konunun daha iyi anlaşılması için Türkçe sözcüklere ağırlık vermiştir. Asırlarca Bulgar halk dilinde yer edinmiş binlerce Türkçe sözcüğün varlığını ve gücünü bilen Tsarski, daha geniş kitlelere ulaşabilmek ve anlaşılır olabilmek için Türkçe sözcükleri bilinçli tercih etmiştir. Ayrıca Bulgarca sözcükleri açıklarken Türkçe sözcüklerden istifade etmiştir. Eserde yaklaşık 700 Türkçe sözcük tespit edilmiştir. Türkçe sözcüklerin yanında farklı Türkçe gramatikal yapılar da görülmektedir. Bunların içinde Türkçe fiillerin kullanılması dikkat çekicidir. El yazmasında Latin harflerinin kullanılması ve Türkçenin temel ünlülerinden “ö” ve “ü” seslerinin gösterilmiş olması 18. Yüzyıl Türkçe ses bilgisi açısından son derece önemlidir. Çalışmada Bulgar Katolik (Pavlikan) dinî metinlerinde geçen Türkçe unsurlar hakkında bilgi verilecek olup Türkçenin dönem itibarıla önemine değinilecektir.

Anahtar kelimeler: Bulgar Katolikler, Pavlikanlar, Türkçenin etkisi, Bulgarca, Bulgaristan

\section{A review of the Turkish elements in a Bulgarian catolic (Paulician) text from the XVIII Century}

\begin{abstract}
The text written by Petar Kovachev Tsarski (Peter Fabri Imperialli) in 1773 and present in the Bulgarian national library "St. Cyril and Methodius", is the oldest written manuscript of the Bulgarian Catholic (Paulician) literature. The writer has translated the work from the Italian to the Bulgarian language and used Latin letters. The first part of the work, comprised from two main parts, is formed from Catholic teachings and prayers and the second part consists of comments regarding the Gospels. The most prominent characteristic of the work is the intensive use of the Turkish elements in it. The writer, who used a plain language, has used Turkish words in order to appeal to the Bulgarian Catholic society. This state of the affairs gives us important hints about the
\end{abstract}

Dr. Öğr. Üyesi, İstanbul Medeniyet Üniversitesi, Edebiyat Fakültesi, Türk Dili ve Edebiyatı Bölümü (İstanbul, Türkiye), abidinkarasu@hotmail.com, ORCID ID: 00oo-0002-2324-111X [Araştırma makalesi, Makale kayıt tarihi: 12.10.2020kabul tarihi: 20.12.2020; DOI: 10.2900o/rumelide.835523

Adres 


\begin{abstract}
presence and the functioning of the Turkish language on the Bulgarian ground in the XVIII century. Especially in the second part of the manuscript, the writer, who explains the life of Jesus, has given weight to the Turkish words in order this topic to be understood in better way. Tsarski, who knew the presence and the strength of the thousands of Turkish words accepted in the Bulgarian folk language, in order to reach the wider public and be understood, deliberately used Turkish words. Except that, when he explained Bulgarian words, he used Turkish words. Approximately 700 Turkish words have been determined in the work. Besides the Turkish words, different Turkish gramatical forms can also be seen. Among them, what especially draws the attention is the use of the Turkish verbs. The use of the Latin letters and the indication of the Turkish cardinal vowels "ö" and "ï" is extremely important from the aspect of the Turkish phonetics of the 18 . Century. In the text, the author will give information about the Turkish elements present in the Bulgarian Catholic (Paulitian) texts and the importance of the Turkish language from the aspect of its period of use.
\end{abstract}

Keywords: Bulgarian Catholics, Paulicians, Turkish İnfluence, Bulgarian, Bulgaria

\title{
Giriş
}

Türkçenin Balkan dilleri üzerindeki etkisi yüz elli yıldan bu yana araştırma konusundur. Özellikle devlet dili veya diğer bir ifadeyle resmi dil seviyesindeki diller üzerine yapılan çalışmaların sayısı oldukça fazladır.

Ancak, Türkçenin Balkanlardaki daha küçük topluluklar üzerinde etkisi yeterince araştırılmamıştır. Bu topluluklardan biri de Bulgar Katolikler (Pavlikanlar)'dir. Roma Katolik Kilisesi'nin 17. Yüzyıldan sonra Bulgar topraklarındaki aktif propagandası neticesinde ortaya çıkan Bulgar Katolik (Pavlikan) edebiyatı Ortodoks Bulgarlardan farklı olarak Latin alfabesini kullanırken, metinlerde kullandığı dil Türkçe sözcüklerinin yoğunluğu bakımından dikkat çekicidir. Bu dil suni oluşturulmuş bir dil olmayıp Bulgar halkının doğal dilidir.

Bulgaristan topraklarında yaşayan Pavlikan toplulukları yıllarca dışlanmış edebiyatları göz ardı edilmiş olup yazılı eserleri bilim çevrelerine kapalı kalmıştır.

Günümüzdeki çalışmalar neticelisinde ylllarca bu sahadaki ön yargılar "izole edilmiş ve sınırl alanlarda kalarak literatürün gelişiminde hiçbir rol oynamadığı" kalkmış ve hak ettiği değeri almıştır. (İstoria, 1962:402). B. Tsonev Bulgaristan Milli Kütüphanesi el yazmaları envanteri üzerinde çalışırken Pavlikan koleksiyonlarının özel bir çalışmayı hak ettiğini not eder (Tsonev, 1923:479).

Son yıllarda, Bulgar Katolik edebiyatı üzerine yapılan araştırmalarda bir artış gözlenmektedir. Bu çalışmalar, Balkanları yakından takip etmemiz hasabiyle dikkatimizi çekmiş, yaptığımız incelemeler neticesinde Türkçenin yazılı Bulgar Katolik dilinde önemli bir işleve sahip olduğu ortaya çıkmıştır.

Araştırma konusu olarak 1773 yllında Petar Kovachev Tsarski tarafından kaleme alınan ve içinde Katolik dini öğretiler ile çeşitli hikâyelerin olduğu el yazması eser seçilmiştir. Yazmada son derece sade bir dil kullanılmıştır. Özellikle eserde kullanılan Türkçe sözcüklerin sayıca fazlalığı, neredeyse her sayfada onun üzerinde Türkçe sözcügün yer alması dikkate değerdir. Ayrıca yazarın hitap ettiği halk kitlesinin anlayamayacağını düşünülerek edebi dilin sözcüklerini cümle içinde Türkçe sözcüklerle açıklaması son derece önemlidir. Bunun yanında Türkçe fiillerin, eklerin ve farklı gramatikal yapıların sıklıkla kullanılması eseri Türkçe açısından ayrıcalıklı kılmaktadır.

\footnotetext{
Adres $\mid$ Address

İstanbul Medeniyet Üniversitesi, Eğitim Bilimleri Fakültesi, Türkçe İstanbul Medeniyet University, Faculty of Education Sciences, ve Sosyal Bilimler Eğitimi Bölümü, Türkce Eğitimi ABD Cevizli Turkish and Social Scinces Education, Turkish Language Teaching Kampüsü, Kartal-İstanbul/TÜRKIYE $\quad$ Education, Cevizli Campus, Kartal-İstanbul /TURKEY e-posta: editor@rumelide.com 1 e-mail: editor@rumelide.com
} 
Bulgar Katolik edebiyatı ile ilgili yapılan çalışmalara bakacak olursa şu çalışmaları görürüz: (Behinyova 1975; Georgiev 1971; Georgiev 1973; Ivanova 1984; Ivanova 1985; Ivanova 1989; Ivanova 1997 a; Ivanova 1997b; Ivanova 1998; Ivanova 1999a; Ivanova 1999b; Ilieva 2011; Stanchev 1975; Stanchev 1981; Stanchev 1988; Stanchev 1995; Stanchev 1998; Tsibranska-Kostova, Abadjieva 2017; Jerkov 1979; Jerkov 1985; Walczak-Mikołajczakowa 2004)

Bulgar Katolik (Pavlikan) edebiyatının kurucularından biri olarak kabul edilen Petar Kovachev Tsarski'nin (Petar F. Imperiali) (Abadzhieva,2017:5), şimdiye kadar bize ulaşan eserleri; metinlerin dil özelliklerini inceleyen birkaç çalışma dışında kapsamlı araştırılarak yayınlanmamıştır. Mariola Volchak Mikolaichakova, 17. ve 18. Yüzyll Bulgar Katoliklerinin edebi çalışmalarına adanmış monografisinde, Petar Kovachev Tsarski'nin eserlerinde kullandığı dil üzerine bir çalışma yapmıştır. (Walczak-Mikołajczakowa 2004). 2015 yılında Oxford Üniversitesi'nden Florence Graham, "Boşnakça ve Bulgarca Fransiskan metinlerinde Türkçe ödünçlemeler üzerine doktora tezini hazırlamıştır (Graham, 2015). Bu çalışma НБKM² 778 ve NBKM 779 adlı iki el yazması Türkçe sözcük örnekleri sunmasının yanında Bulgar Katoliklerin, özellikle Petar Kovachev Tsarski'nin edebi dilinin tanıtılması ve çözümlemesine büyük katkı sağlamıştır.

Yine, Bulgar Bilimler Akademisi öğretim üyesi Dr. Magdalena Stefanova Abadzhieva'nın Bulgar Katolikleri (Pavlikanlar) üzerine önemli çalışmaları mevcuttur: (Abadzhieva, 2014), (Abadzhieva, 2013), (Abadzhieva, 2014), (Abadzhieva, 2014), (Abadzhieva, 2014), (Abadzhieva, 2017), (Abadzhieva, 2015).

Abadzhieva’nın 2017 yılında tamamlanan “Bulgar Dili Tarihinde 18. Yüzyıl Pavlikan Edebiyatı” başlıklı doktora tezinden ve Prof. Dr. Marıyana Tsıbranska-Kostova ile birlikte hazırladıkları "17-18. Yüzyllar Arasındaki Katolik Edebiyatında Yabancı Unsurlar (Filip Stanislavov'un Abagar'ı ve Petar Kovachev Tsarski’nin 778 numaralı El yazması)" adlı çalışmalarından önemli ölçüde istifade ettik. Özellikle Abadzhieva'nın alana katkıları son derece önemli olduğu söylenebilir.

Ancak burada bahsedilen çalışmalardan hiç biri doğrudan Türkçenin etkisini incelemeye yönelik değildir.

Alandaki bu boşluktan yola çıkarak Bulgar Katolik (Pavlikan) edebiyatının ilk yazılı eserlerinden olan NBKM 778 numaralı ve 1773 tarihli el yazması eser incelenmiştir.

Çalışmada:

- Petar Kovachev Tsarski'nin hayatı ve eserleri hakkında bilgi verilmiştir.

- Yazmada 700’e yakın Türkçe sözcük tespit edilerek sözcüklerin günümüzdeki anlamları verilmiştir.

- “ö” ve “ü” harflerinin kullanımı hakkında bilgi verilmiştir.

- Bulgar edebi dilinin sözcüklerinin cümle içinde Türkçe sözcüklerle açıklanması hadisesi üzerinde durulmuştur.

- Örnek bir sayfa seçilerek Türkçe sözcüklerin kullanım sıklığı gösterilmiştir.

- Türkçe fiillerin nasıl kullanıldığı ve gördükleri vazifeler ele alınmıştır.

- Farklı Türkçe gramatikal yapılar hakkında bilgi verilmiştir.

\footnotetext{
2 НБКМ Народна Библиотека Кирил и Методий- Bulgar Milli Kütüphanesi’nin kısaltması olup diğer sayfalarda NBKM şeklinde gösterilecektir.
İstanbul Medeniyet Üniversitesi, Eğitim Bilimleri Fakültesi, Türkçe İstanbul Medeniyet University, Faculty of Education Sciences, ve Sosyal Bilimler Eğitimi Bölümü, Türkce Eğitimi ABD Cevizli Turkish and Social Scinces Education, Turkish Language Teaching Kampüsü, Kartal-İstanbul/TÜRKIYE Education, Cevizli Campus, Kartal-İstanbul /TURKEY

Adres $\mid$ Address e-posta: editor@rumelide.com 1 e-mail: editor@rumelide.com
} 
Yapılan çalışmayla, 18. Yüzyıl Bulgar Katolik (Pavlikan) edebi dilinin oluşumunda Türkçenin etkisi ve işlevini ortaya koyarak eserin tanıtımı hedeflenmiştir.

\section{Petar Kovachev Tsarski ve eserleri hakkında bilgi}

Peter Kovachev Tsarski hakkında çok az şey bilinmektedir. 1745 - 1746 yılları arasında doğduğu tahmin edilmektedir (Starobılgarska Literatura, 2003:361). Derlemelerinden biri olan 1793 tarihli 1423 NBKM 'nin başlık sayfasından yazarın 49 yıl yaşadığı ve 24 Şubat 1795'te öldüğü anlaşılmaktadır.

Doğum yeri hakkındaki bilgiler çelişkilidir. Peter Kovachev Tsarski ile ilgili en eski veriler G. Giev tarafından 1937'de yazılan "Plovdiv Piskoposluğunda Doğan Bulgar Rahiplerin, Pavlikanlarm Vaftizinden Günümüze Kadar Olan Kısa Biyografileri" adlı çalışmada bulunmaktadır. Buradan yazarın Plovdiv civarında bir yerde doğduğu anlaşllıyor, ancak kesin yer belirtilmemiştir (Abadzhieva, 2017:9).

Eğitimini Roma'da tamamladığı hakkında bilgiler mevcuttur. Roma'daki eğitimini tamamladıktan sonra Plovdiv Piskoposluğu'nun apostolik papazı olarak görev yapmış ve 1794'ten ölümüne kadar, şimdiki Hisarya şehrinin bir semti olan Davudzhovo'nun Miromir köyünde hizmet etmiştir (Giev, 1937:107).

Petar Kovachev Tsarski'nin1773 yllına yazdığı ve Çağdaş Bulgar Katolik Edebiyatının bize ulaşan en eski el yazması örneği olan № 778 numaralı yazma Bulgaristan Milli Kütüphane'sinde muhafaza edilmektedir. Bilim çevrelerinde yakın zamana kadar, el yazmalarından dördü biliniyordu: 1773 tarihli NBKM 778, 1780 tarihi NBKM 779, 1793 tarihli NBKM 1423. En son bilgilere göre dördüncüsü 1779 ylında yazılmış olup Roma'da bulunmaktadır (Abadzhieva,2017:9).

Yazar, diğer eserlerinde olduğu gibi № 778 numaralı el yazmasında da Latin alfabesini kullanmıştır. Alfabe tercihi, bu döneme ait tüm Katolik edebiyatının karakteristik bir özelliği olup yazarların dini Roma Katolik aidiyetleriyle doğrudan bağlantılıdır. El yazması № 778 İtalyancadan Bulgarcaya çevrilmiştir.

İki ana bölüm halinde inceleyebileceğimiz yazmanın birinci bölümü Katolik öğretileri ve dualarından oluşmakta olup ikinci bölümü ( 51- 258. sayfa araları) İncil'den bilgilere yer verilmiştir.

\section{Türkçe unsurlar hakkında değerlendirme}

Peter Kovachev Tsarski, kaleme aldığı derlemesinde çok sayıda Türkçe sözcüğe yer vermesi, yazdıklarının halk tarafından daha kolay anlaşılmasını istemesi neticesindendir. Bu dönemde yazılan eserlerin çoğunda bu özellikler görülmektedir. Dönem yazarları, dillerini daha anlaşılır kılmak için Türkçe sözcükleri bilinçli kullanmışlardır. K. Mirchev, 1802 tarihli el yazmasında Sofroniy Vrachanski'nin bir cümlesinden alıntı yaparak şunları yazmıştır: " Bu dönemde Türk topraklarında yaşayan Bulgarlar, aralarında sıklıkla Türkçe konuşmakta olup kendi dillerini unutmuşlardı." (Abadzhieva,2017:131).

El yazmasının ikinci bölümünde İncil'in tanıtımına yer vermiştir. Hz. İsa'nın hayatının büyük ölçüde anlaşılır ve erişilebilir kılma arzusu, yaşayan bir dilin kullanılmasını gerektirmekteydi. Metnin birçok yerinde yazarın edebi kelimeleri Türkçe sözcükler kullanarak açıklaması bilinçli bir tercihtir. Bu veri

\footnotetext{
Adres $\mid$ Address

İstanbul Medeniyet Üniversitesi, Eğitim Bilimleri Fakültesi, Türkçe İstanbul Medeniyet University, Faculty of Education Sciences, ve Sosyal Bilimler Eğitimi Bölümü, Türkce Eğitimi ABD Cevizli Turkish and Social Scinces Education, Turkish Language Teaching Kampüsü, Kartal-İstanbul/TÜRKIYE $\quad$ Education, Cevizli Campus, Kartal-İstanbul /TURKEY e-posta: editor@rumelide.com 1 e-mail: editor@rumelide.com
} 
dönem itibariyle Türkçenin ne kadar yaygın olduğunu, halkın sözcük dağarcığında ne denli yer edindiğini göstermektedir.

Petar Kovachev Tsarski 'nin eserindeki Türkçe unsurları tüm yönleriyle belirlemek daha kapsamlı bir çalışmayı gerektirmektedir. Yaptığımız çalışmada Bulgar Katolik metinlerinde Türkçe sözcüklerinin kullanımına dikkat çekmeyi amaçlamaktayız. El yazmasındaki bazı Türkçe unsurları aşağıda göstereceğiz.

\section{Bulgarca sözcüklerin Türkçe sözcüklerle açılanması}

Metinde dikkat çeken diğer bir husus, Bulgar edebi dilinin sözcüklerinin cümle içinde Türkçe sözcüklerle açıklanma kaygısıdır. Özellikle el yazmasının ikinci bölümünde Hz. İsa'nın hayatının konu edildiği satırlarda halkın daha rahat anlaması için Bulgarca sözcüklerden hemen sonra eş anlamlı Türkçe sözcükler kullanılmıştır.

18. Yüzyılın ikinci yarısındaki bu oluşum, Bulgar toplumunun iki dilliliğini ve Türkçenin halk ă̆ızlarındaki durumunu tespit için son derece önemlidir.

Bulgarca sözcüklerin Türkçe sözcüklerle açılanması şu şekildedir:

\section{a. Bulgarca sözcüğün Türkçe sözcükle açılanması}

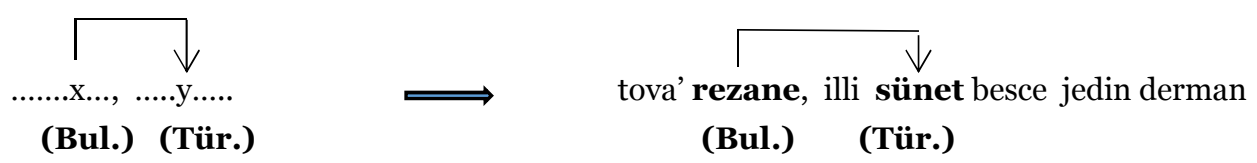

\section{b. Türkçe sözcüğün Bulgarca sözcükle açıklanması}

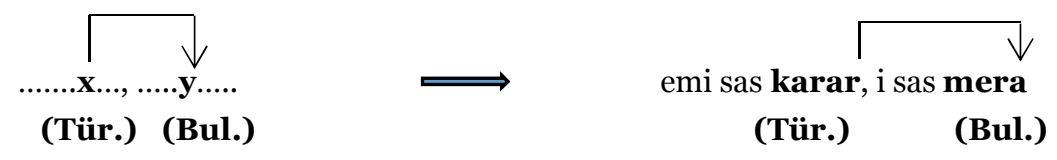

\section{c. Türkçe sözcüğün Türkçe sözcükle açılanması}

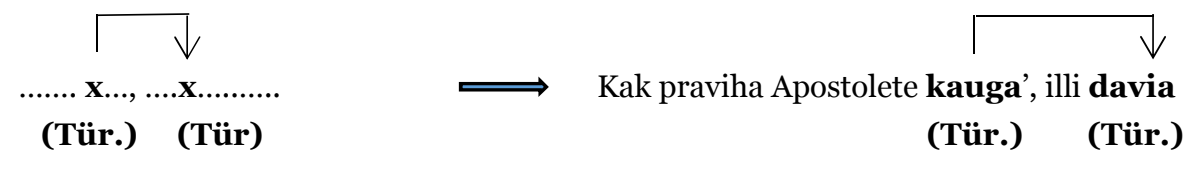

\footnotetext{
Adres $\mid$ Address

İstanbul Medeniyet Üniversitesi, Eğitim Bilimleri Fakültesi, Türkçe İstanbul Medeniyet University, Faculty of Education Sciences, ve Sosyal Bilimler Eğitimi Bölümü, Türkce Eğitimi ABD Cevizli Turkish and Social Scinces Education, Turkish Language Teaching Kampüsü, Kartal-İstanbul/TÜRKIYE $\quad$ Education, Cevizli Campus, Kartal-İstanbul /TURKEY e-posta: editor@rumelide.com 1 e-mail: editor@rumelide.com
} 


\section{1. bahçe > bahcia - rai (paй)}

"rai” Bulgarcada cennet anlamında kullanılmaktadır. Yazar "rai” sözcügünü cümle içinde açıklamak için "bahçe”, güzel bahçe sözcüğünden istifade ediyor.

“...i turnaghi u zemelskiet Rai, sanki u jedna' hubava bahcia...”

2. güç > ghiücno - macno (мъчно)

“...macno, tescko, ghiücno..."

\section{3. kahır > kahar - grixia (грижа)}

“... bes grixia, i kahar nikakav...”

4. sünnet > sünet - rezane (резане)

“... tova' rezane, illi sünet besce jedin derman...”

\section{5. sahip > saibia - gospodar(господар)}

“... koi sctesce dae' gospodar, i Saibia od sickiet svet...”

\section{6. kavga > kauga - dava > davia (давия)}

Bazı cümlelerde Türkçe sözcükten sonra yakın yada eş anlamlısı da Türkçe sözcükle açıklanmaya çalışılmıştır. Aşağıdaki örnekte bunu görüyoruz.

“... Kak praviha Apostolete kauga', illi davia ...”

\section{7. akıllı > akallia - mudar (мъдър)}

“mudar (мъдър)" Bulgarcada akıllı anlamında kullanılmaktadır. Yazar “mudar (мъдър)” sözcüğünü cümle içinde açılamak için "akıllı" bahçe sözcüğünden istifade ediyor.

“Tei i Gospodin Boogh, detoe' po’ mudar, i po' akallia bes krai od zarete od tozi svet, za' tazi nai golema rabota isbra' jedin Angel od nai golemite"

\section{8. kuvvet > kovet - silla(сила)}

“Ne produma vekie duma Sveti Ivan, ciunki vide', ci tazi besce voglia Isskukrastova, krastigo, i sas tova' krasctene Issukras posveti vodata, i dadei kovet, i silla da moxe, da ucisti duscite od greh, i na tozi ces Issukras zadade negovoto krasctenie.”

\section{9.sıklet >saklet - grixia (грях)}

"I Gospodin Boogh nescte vekie da tarpi tia da teghlat tazi grixia, i tozi golem saklet, emise nakani da imgo mahni od serzeto i daghi zaradova”

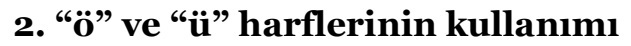

Tsarski’nin eserinde "ü” ve "ö" harflerini kullanması aldığı eğitim ve temsilcisi olduğu Katolik mezhebiyle doğrudan bağlantılıdır.

\footnotetext{
Adres $\mid$ Address

İstanbul Medeniyet Üniversitesi, Eğitim Bilimleri Fakültesi, Türkçe İstanbul Medeniyet University, Faculty of Education Sciences,

ve Sosyal Bilimler Eğitimi Bölümü, Türkçe Eğitimi ABD Cevizli Turkish and Social Scinces Education, Turkish Language Teaching

Kampüsü, Kartal-İstanbul/TÜRKIYE $\quad$ Education, Cevizli Campus, Kartal-İstanbul /TURKEY

e-posta: editor@rumelide.com 1 e-mail: editor@rumelide.com
} 
Elimizdeki kısa özgeçmişinden Petar Kovachev Tsarski'nin eğitimini İtalya'nın Roma şehrinde tamamladığını biliyoruz. 18. Yüzyılın ikinci yarısında Roma'da Güney Slav topraklarından gelen gençleri misyoner ve rahip için hazırlayan sayıca çok fazla okul vardı. Petar Kovachev Tsarski Roma'da eğitimi sırasında İtalyancanın yanında Hırvatçayı da öğrenmiştir.

Hırvat topraklarındaki Latin alfabesi esas olarak iki farklı etki neticesinde şekillenmiştir, güney kesimlerde İtalyancanın; kuzeyde ise Macarca etkili olmuştur (Abadzhieva,2017:106).

Macarcada "ö" ve "ü" harflerinin kullanılması Petar Kovachev Tsarski'nin № 778 numaralı el yazmasında kullandığı harf sistemine girmelerinin en olası nedenidir (Tsibranska ve Abadzhieva, 2016: 28).

Arap harflerinin kullanıldığı bir dönemde Latin harfleriyle kaleme alınan el yazmasında Türkçenin temel ünlülerden olan “ö" ve "ü” sesleri gösterilmiş olması 18. Yüzyıl Türk dil tarihi açısından önem arz etmektedir.

\section{“ü”sesi}

güç > ghiücno (778:63), sünnet > sünet (778:71), türlü > türlie (778:80), düzen > dïzen (778:89), müsaferet $>$ müiscefere (778:111), müjde $>$ müixde (778:114), sürek > sürek (778:117), döşek $>$ düscek (778:119), gümrük > ghiumrïk (778:120), güçlendi > ghï̈clendissa (778:159), kürek > kï̈rezi (778:164)

\section{“ö” sesi}

örnek > örnek (778:57), öfke > 畨keto (778:91), hüküm > hökium (778:110), göl > ghiöl (778:126), öyle ise $>\underline{\text { öileise }(778: 139)}$

\section{3. “sanki” zarfı ve "çünkü" bağlacının kullanımı}

\section{1. "sanki > sanki" zarfinın kullanımı}

Yapılan inceleme neticesinde metinde 143 farklı cümlede "sanki” zarfının kullanımı tespit edilmiştir.

Metinde kullanılan "sanki” zarfının örnekleri şu şekildedir:

Duma Sveti Luca , ci mlogo halk slededesce Issukrasta na sekade, kadeto hodesce, i imasce nekoi , i druga xená , detogo sledesce, sanki sveta Maria Madalena. (Aziz Luca söylemişti: Her yerde halk Issukrasta'yı takip ediyordu, başka biri de vardı onu takip eden sanki Maria Magdalena) (778:143)

Dase miesc cesto besce jedin adet od Cifuttete, da produmasc karsci, sanki ci ne trebovasce tolkos miti , moxesce da bade sebep od golema ubarkaniza , i kaugá . (... onlara karşı konuşmak sanki büyük bir kavganın habercisiydi...)(778:149)

\section{2. "çünkü > ciunki” bağlacının kullanımı}

Yapılan inceleme neticesinde metinde 69 farklı cümlede "çünkü > ciunki" bağlacının kullanımı tespit edilmiştir.

Metinde kullanılan “çünkü > ciunki” bağlacının örnekleri şu şekildedir:

Adres

İstanbul Medeniyet Üniversitesi, Eğitim Bilimleri Fakültesi, Türkçe ve Sosyal Bilimler Eğitimi Bölümü, Türkçe Eğitimi ABD Cevizli Kampüsü, Kartal-İstanbul/TÜRKIYE e-posta: editor@rumelide.com 
"I ciunki tezi dni cifuttete imaha paskelé , zatová beha doscle mlogo hora od tiurliu tiurliu viljate..." (Farklı farklı vilayetlerden pek çok insan gelmişti çünkü Çıfıtların (Yahudi) Paskalya bayramı vardı.) (778:252)

"Ama ciunki rabotata, deto imasce dase isvarsci, besce nai golema, i nai sveta od sickite rabote Boxi...” ( Ama, çünkü yapılacak işler içinden Allah katındaki en mühim işti...) (778:56)

“...ci kral Erode, ciunkise useti, ci behago izmamili trite zaré i behase varnali na viljatatsi iz drughi patt...” ( Üçü de farklı yollardan şehre döndüler, Kral Erode anladı, çünkü onu aldatmışları) (778:56)

“...ciunki Gospodin Boogh ima adet da slaga hudulete, i da izdiga onezi, detose slagat, i tei stori tozi patt ...” (...çünküi Allah sınır koyar..)(778:100)

\section{Türkçe fiillerin kullanılma şekilleri}

Eserde dikkat çekici unsurlardan biri de Türkçe fiillerin kullanılmasıdır. Sözcüklerin yanında fiillerin kullanımı gramatikal etkiyi göstermektedir.

NBKM 788 numaralı el yazmasında yüzün üzerinde Türkçe fiil kullanılmıştır.

Görülen geçmiş zaman ekiyle çekimlenen Türkçe fiil Bulgarcanın “+ca (sa)” ekini aldığı zaman jajaldissa < yayıldı fiil Bulgarcada görülen geçmiş zaman ifadesini korumaya devam etmiştir. Bulgarcada ve diğer Balkan Slav dillerinde kullanılan “+ca (sa)” eki Yunancadan geçmiştir (Yenisoy, 2007:182).

$[\{$ türkçe fiil $\}+\{$ g.g.z.e $\}+\{$ sa $\}]=>$ jajal + di + s(s)a $<$ yayıldı

kon- > kondissat (778:67)

“...da trassat pó vanka nekoi kolipka da kondissat , i nameriha jedná koliba viran...” (Dışarıda konmaları için bir baraka arasınlar, buldukları baraka virandı.)

uy- > uidissat (778:68)

“...ciunki tia nesctat da uidissat na diavlat...” (Çünkü bunlar devlete uymak istemiyorlar)

zorla- > zorladissa (778:76), yayl- > jajaldissa (778:77), rast gel- > razgheldissase (778:83), şüphele- > sciubelendissat (778:83), bayl- > bajaldissa (778:96) uy- > uidissa (778:105), say- > saidissaha (778:118), güçlen- $>$ ghiuclendissa (778:139), tuttur- $>$ tutturdissa (778:197), muhurledissa (778:233), say- > saidissova (778:252), kes- > kestissame (778:74), karış- > karasctissa (778:75)

Görülen geçmiş zaman ekiyle çekimlenen Türkçe fiil Bulgarcanın “+ca” ve “+ yвa” ( + sa + uva ) naslandissovat < nazlanıyorlar eklerini aldığı zaman görülen geçmiş zaman eki, fonksiyon olarak şimdiki zamanı belirtir ve süreklilik anlamı kazanır (Leontik, 2016: 32).

$[\{$ türkçe fiil $\}+\{$ g.g.z.e $\}+\{(\mathrm{s}) \mathrm{sa} / \mathrm{o}\}+\{\mathrm{u} /$ ova $\}]=>$ naslan $+\mathrm{di}+\mathrm{ss}(\mathrm{a} / \mathrm{o})+\mathrm{u} /$ ova $<$ nazlanıyorlar

nazlan- > naslandissovat (778:168), art- > artissovasce (778:183), hizmet et- > hizmetuvasce (778:87)

\section{Türkçe sözcüklerin kullanım sıklığı}

Petar Kovachev Tsarski eserini kaleme alırken halkın anlayacağı sade bir kullanmıştır.

\begin{tabular}{|c|c|}
\hline Adres & Address \\
\hline İstanbul Medeniyet Üniversitesi, Eğitim Bilimleri Fakültesi, Türkçe & İstanbul Medeniyet University, Faculty of Education Sciences, \\
\hline ve Sosyal Bilimler Eğitimi Bölümü, Türkçe Eğitimi ABD Cevizli & Turkish and Social Scinces Education, Turkish Language Teaching \\
\hline $\begin{array}{l}\text { Kampüsü, Kartal-İstanbul/TÜRKIYE } \\
\text { e-posta: editor@rumelide.com }\end{array}$ & $\begin{array}{l}\text { Education, Cevizli Campus, Kartal-İstanbul /TURKEY } \\
\text { e-mail: editor@rumelide.com }\end{array}$ \\
\hline
\end{tabular}


Aşağıda örnek bir paragrafını verdiğimiz NBKM 778 numaralı el yazması metninde Türkçe sözcüklerin kullanım sıklığı görülmektedir.

[101. sayfa]

pak utide na Ierusalem da pravi Velikden . I kogá ulezi u Cerquata , vidé tuka mlogo , deto praveha aliscverisc , i prodavaha, i kupuvaha ovze, volove, galabe, i drughe xivine za kurban . Vidé pak drughi, deto imaha pred sebesi jedin kup od pari, i davaha na faidá . Popovete od Cerquata davaha izin dase pravi tozi aliscverisc, u Cerquata zarat Iabangiete, da moxiat sanki da namerat na gotovo sicko, kogá iskaha da pravat kurban . Ama Issukras ne aressa tová, zeré duma Sveti Ivan Evanghelista, ci kato vidé toi tazi' rabota , napravi jedin bicc od vaxé , i zakaci da bii sickite alisc verisccie ; i tei ispadi sickite xivine, deto beha tam, i onezi detoghi prodavaha : rassipa parite na memeleghiete pó zemeta : i rece na sicki : mahnetese od tuka, i nedeite pravi kascta Boxia , mesto od alisc verisc . Dumat sickite okomusce , ci kogá Gospodin Boogh Issukras stori tazi rabota , i padesce Bazirghianete od Cerquata , izlazescemu od negovoto Boxij lize jedná svetlos , detoghi uplasci sicki, i makar toi da besce samzi , pak nijedin moxé damuse upré , illi damu recé nescto . Sled tazi rabota utidoha pré nego sickite glavi Evraiske, i popitahago sas kakav hökium besce storil toi tazi rabota ; i ako Gospodgo besce pratil , daim da

alış veriş $>$ aliscverisc, kurban $>$ kurban, fayda $>$ faidá, küp $>$ kup, yabancı $>$ Iabangiete, sanki $>$ sanki, zere ${ }^{3}>$ zere, muameleci ${ }^{4}>$ memeleghiete, okumuş $>$ okomusce, hüküm $>$ hökium

\section{Yazmada kullanılan sözcüklerden örnekler}

El yazması eserde 70o’e yaklaşı Türkçe sözcük mevcuttur. Sözcüklerden bir kısmı aşağıda verilmiş olup günümüz Türkiye Türkçesindeki karşılıkları yazılmıştır. Aşağıdaki sözcükler Abadzhieva’nın çalışmasından alınmıştır (Abadzhieva, 2017:135).

\begin{tabular}{|c|c|c|}
\hline $\begin{array}{l}\text { adet }>\text { adet } \\
\text { ağa }>\text { agalarka } \\
\text { açık }>\text { acik } \\
\text { acımak }>\text { agiadissa } \\
\text { akıl }>\text { akal } \\
\text { akıbet }>\text { akibet } \\
\text { alay }>\text { alai } \\
\text { el alem }>\text { alalem } \\
\text { alçak }>\text { alciak } \\
\text { alış veriş }>\text { alisc verisc } \\
\text { ancak }>\text { angiak } \\
\text { ahretlik }>\text { aratlikat } \\
\text { ortak }>\text { artak } \\
\text { askerler }>\text { askerat } \\
\text { aslında }>\text { aslindan } \\
\text { avcı }>\text { avgie } \\
\text { baylld }>\text { bajaldissa } \\
\text { balgam }>\text { balgame } \\
\text { beraber }>\text { barabar } \\
\text { barışk }>\text { barasciak } \\
\text { barısmak }>\text { barasctissa } \\
\text { başarmak }>\text { basciardissat } \\
\text { başka }>\text { bascka }\end{array}$ & $\begin{array}{l}\text { gemi }>\text { ghemie } \\
\text { getir- }>\text { ghetirttissa } \\
\text { haber }>\text { habar } \\
\text { haham }>\text { hahamin } \\
\text { hayır }>\text { hair } \\
\text { hayvan }>\text { haivane } \\
\text { halk }>\text { halk } \\
\text { helalleş- }>\text { halalsctissa } \\
\text { hamarat }>\text { hamarat } \\
\text { haraç }>\text { harac } \\
\text { hata }>\text { hataile } \\
\text { hatır }>\text { hatar } \\
\text { hekim }>\text { hekime } \\
\text { hesap }>\text { hesap } \\
\text { hizmet et - > hizmetuva } \\
\text { fodul }>\text { hodule } \\
\text { ikram }>\text { ikram } \\
\text { işkillen- }>\text { isckelendissova } \\
\text { kabahat }>\text { kabahat } \\
\text { kabil }>\text { kabil } \\
\text { kaçır- }>\text { kaciardissat } \\
\text { kahırlan- }>\text { kaharuvasce } \\
\text { kalabalık > kalabalak }\end{array}$ & $\begin{array}{l}\text { miras }>\text { miras } \\
\text { nişan }>\text { miscian } \\
\text { mühürle- }>\text { muhurledissan } \\
\text { münafikla->munafakladissat } \\
\text { mundar ol }>\text { mundardissano } \\
\text { mızrak > } \text { musdrak } \\
\text { nazlan- }>\text { naslandissovat } \\
\text { nekes }>\text { nekezlik } \\
\text { niyet }>\text { niet } \\
\text { okumuşum }>\text { okumusciam } \\
\text { o saat }>\text { osahat } \\
\text { oturmak }>\text { oturdissa } \\
\text { paralamak }>\text { paraladissovaha } \\
\text { patırtı }>\text { patardia } \\
\text { pişman }>\text { popiscmani } \\
\text { renk }>\text { renk } \\
\text { rezillik }>\text { rezillik, rezillicat } \\
\text { saat }>\text { sahat } \\
\text { sahip }>\text { saibia } \\
\text { saydı }>\text { saidissa } \\
\text { saygınlk }>\text { saighilik } \\
\text { sahip }>\text { saip } \\
\text { slkılmak }>\text { sakaldissovane }\end{array}$ \\
\hline
\end{tabular}

3 Çünkü (TDK- DS.)

4 Para, senet, tahvil vb.nden kazanç sağlayan, bankerlik yapan kimse

\begin{tabular}{|c|c|}
\hline Adres & Address \\
\hline İstanbul Medeniyet Üniversitesi, Eğitim Bilimleri Fakültesi, Türkçe & İstanbul Medeniyet University, Faculty of Education Sciences, \\
\hline $\begin{array}{r}\text { Kampüsü, Kartal-İstanbul/TÜRKIYE } \\
\text { e-posta: editor@rumelide.com }\end{array}$ & $\begin{array}{l}\text { Education, Cevizli Campus, Kartal-İstanbul /TURKEY } \\
\text { e-mail: editor@rumelide.com }\end{array}$ \\
\hline
\end{tabular}




\begin{tabular}{|c|c|c|}
\hline bekçi > bek & kılıç > kalac & siklet >saklet \\
\hline birlik > birlik & kapıcı> kapugiike & şaşmak >sciasctissa \\
\hline boyunduruk>bojundruk & karar > karar & şahitlik>scehadlik \\
\hline bulandırma > bulandardiss & kararsız $>$ kararsiz & şüphelenmek>sciubelendissa \\
\hline bulaşmak > bulusctissovaha & karış- > karasctissa & sebep > sebep \\
\hline kabahat >cabahat & karma karışık > karma & seymen $>$ seimenin \\
\hline kabil >cabil & karışık > karascik & seyir $>$ seir \\
\hline kamış >camisc & kahır > kahar & sünger $>$ siungher \\
\hline kanlı >canlia & kail > kail & sundurma $>$ sundurni \\
\hline çember >cember & garezli > kareslia & tabiat $>$ tabiet \\
\hline garez $>$ cares & karşı > karsci & tafra $>$ tafralik \\
\hline garezli > careslie & kıskan- > kascandissova & toprak >toprak \\
\hline karşılık > carscilik & kıskanç > kaskangia & tebdil>tebdil \\
\hline çalışmak >cialasctissa & keyifsiz > kefsiz & teslim $>$ teslim \\
\hline çürümek > ciurudissa & keskin > keskin & toprak>toprak \\
\hline konmak > condissa & kes- > kestissame, kestissa & uymak > uidissa \\
\hline dava $>$ davia & kavga $>$ kauga & uygun > uigun \\
\hline davranmak >davrandissa & kıymetli > kiimetlia & vilayet > viljat \\
\hline doğramacılık>duramagilik & kolay > kolai & viran > viran \\
\hline derman >derman & kullan- > kolandissala & zahmet >zahmet \\
\hline eksik > eksik & konak > konak & zapt > zapt \\
\hline eşkal > esckil & kon- > kondissa & zeytin > zeitin \\
\hline feragat et->ferattissa & kuvvet $>$ kovet & zor $>$ zor \\
\hline izin $>$ izin & kurtul- > kurtulissam & zorlamak<zorladissa \\
\hline yabancı > jabangia & merdiven $>$ merdevenat & \\
\hline yayıl- >jajaldissa & mertebeli $>$ mertebelia & \\
\hline yüzbaşı >jusbascia & medrese $>$ medresse & \\
\hline cenk > genk & memleket > memleket & \\
\hline
\end{tabular}

\section{Sonuç}

Yapılan araştırmayla Türkçenin sadece resmi dil statüsündeki dilleri değil daha küçük toplulukların dillerine de etki ettiği tespit edilmiştir.

Asırlarca, Osmanlı'nın idaresinde barış ve huzur içinde yaşamış olan Bulgar Katolikler (Pavlikanlar)'in dilindeki yüzlerce Türkçe unsur, Türkçenin bu dildeki varlığı ve etki derecesini göstermektedir.

Türkçe Bulgar Katolik (Pavlikan) diline sadece sözcük değil, önemli gramatikal yapılar da vermiştir. Yazarın Türkçe sözcüklere özel önem verdiği görülmektedir. Bu ilginin sebebi halk tarafından daha rahat anlaşılma kaygısıdır.

Bulgar Katolikler (Pavlikanlar) Latin harflerini kullanmaları, eserlerinde sıklıkla Türkçe unsurlara yer vermeleri onları diğer mezheplerden farklı bir yazılı geleneğin temsilcileri haline getirmiştir.

Arap harflerinin kullanıldığı bir dönemde, Latin harfleriyle kaleme alınan el yazmasında Türkçenin temel ünlülerden olan "ö" ve "ü" seslerinin gösterilmiş olması 18. Yüzyıl Türkçe ses bilgisi açısından önem arz etmektedir. 
Bulgar edebi dilinin sözcükleri veya halk tarafından anlaşlamayacağı düşünülen sözcüklerin, cümle içinde Türkçe eş anlamlı sözcüklerle açıklanması dönem itibariyle Türkçenin yaygınlığını ve halkın Türkçe bilgisini yansıtmaktadır.

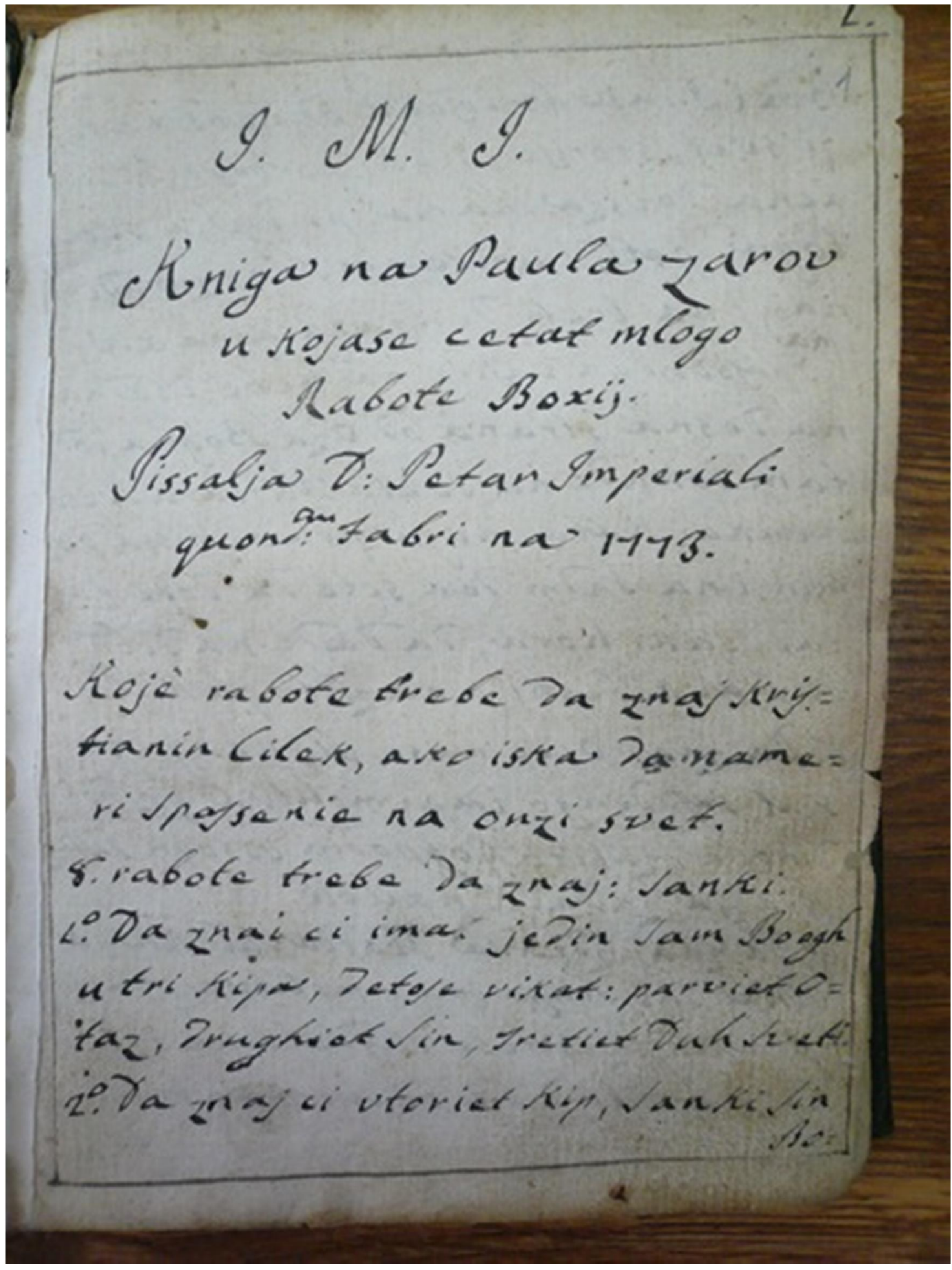

Resim 1: NBKM 778 numaralı yazmanın birinci sayfası

\begin{tabular}{|c|c|}
\hline 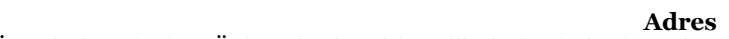 & Address \\
\hline tanbul Medeniyet Üniversitesi, Eğitim Bilimleri Fakültesi, Ti & İstanbul Medeniyet University, Faculty of Education Sciences, \\
\hline kçe Eğitimi ABD Cevizli & Turkish and Social Scinces Education, Turkish Language Teaching \\
\hline $\begin{array}{l}\text { Kartal-Istanbul/TURKIYE } \\
\text { ta: editor@rumelide.com }\end{array}$ & $\begin{array}{l}\text { Education, Cevizli Campus, Kartal-İstanbul /TURKEY } \\
\text { e-mail: editor@rumelide.com }\end{array}$ \\
\hline
\end{tabular}


148 / RumeliDE Journal of Language and Literature Studies 2020.21 (December)

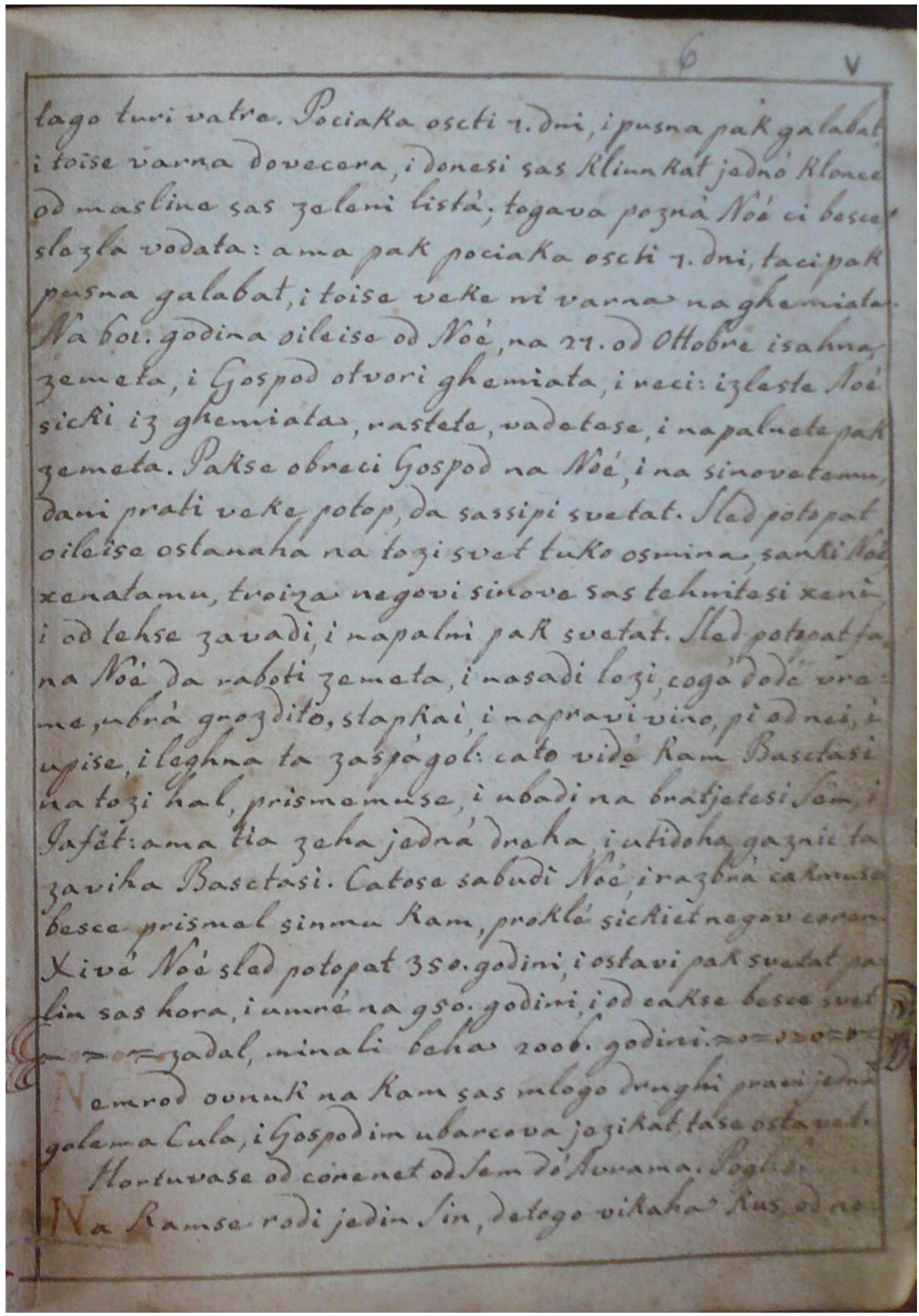

Resim 2: NBKM 778 numaralı yazmandan örnek 


\section{Kaynakça}

Abadzhieva, M. (2013). Ezikıt na pavlikyanskata knizhnina ot XVII vek. - Bılgarski ezik, Prilozhenie, s. 262 - 273. ISSN 0005-4283.

Abadzhieva, M. (2014a). Pavlikyanskata knizhnina ot XVIII v. - primer za knizhoven ezik na narodna osnova. - V: Pismenoto nasledstvo i informatsionnite tekhnologii. S., s. 235 - 238. ISBN 978954-978-725-2.

Abadzhieva, M. (2014b). Knizhoven ezik na narodna osnova li e pavlikyanskata knizhnina ot vtorata polovina na XVIII v. - Palaeobulgarica, 4, s. 68 - 79. ISSN 0204-4021.

Abadzhieva, M. (2014c). Hristiyanskata leksika v rıkopis № 778 na katolicheskiya knizhovnik Petır Kovachev Tsarski. - V: Ime i svyatost, godishnik na asotsiatsiya „Ongll“, t. 13, god. IX, ISSN $1311-493 \mathrm{KH}$.

Abadzhieva, M. (2014d). Pavlikyanskata knizhnina i kharakterniyat za pavlikyanskiya govor fonemen prekhod è> ù. - Littera et Lingua, elektronno spisanie, t. 11, kn. 1/2, ISSN 1312-6172.

Abadzhieva, M. (2017). Predpostavki za vŭznikvaneto na literaturata na bŭlgarite katolitsi na novobŭlgarski ezik prez XVIII v. Katolicheskata propaganda sred pavlikyanite. - V: Vyara i kult, godishnik na asotsiatsiya „Ongŭl“, t. 15, god. XI, s. 221 - 231. ISSN 1311-43X

Abadzhieva-İordanova, M. S. (2017). Pavlıkyanskata Knızhnına Ot XVIII Vek v Istorıata Na Bŭlgarskıya Ezık. Institut za bŭlgarski ezik „Prof. Lyubomir Andrě̆chin” - BAN, Doktora Tezi.

Georgiev, E. (1971). Barok v Bllgarskata Literatura, Literaturna Misll, s.46-62

Georgiev, E. (1973). Bllgarskoto Obshtoistorichesko i Literaturno Razvitie i Barokit. - V: Sb. Bulgarskata Literatura v Obshtoslavyanskoto Literaturno Razvitie, s. 179-203.

Giev, Georgi (1937). Kratki Biografii na Sveshtenitsite - Bılgari, Rodeni v Plovdivskata Eparkhiya, ot Pokrıstvaneto na Pavlikyanite do Dnes. - V: Kalendar Sv. Kiril i Metodiǔ za s. 107.

Graham, Frorence (2015). Turkish Loanwords in Seventeenth- and Eighteenth-Century Bosnian and Bulgarian Franciscan Texts. University of Oxford.

Ilieva, İ. (2011). Bılgarskiyat ezik v predistoriyata na komparativnata lingvistika i v ezikoviya svyat na ranniya evropeĭski modernizım, Blagoevgrad.

Istoriya (1962): Istoriya na Bllgarskata Literatura. T. 1. Starobılgarska Literatura, S.

Ivanova, N. (1984). Iliriǔskiyat Ezik Na Yuzhnite Slavyani v Bilgarskoto Knizhovnoezikovo Razvitie Prez XVII vek. - V: Godishnik Na SU. FSF, t. 78/1, kn. I. Ezikoznanie, Sofiya, 34-93 (Chast I).

Ivanova, N. (1985). Iliriǔskiyat Ezik na Yuzhnite Slavyani v Bllgarskoto Knizhovnoezikovo Razvitie Prez XVII vek. - V: Godishnik na SU. FSF, t. 79/2, kn. II. Ezikoznanie, Sofiya, 3-48 (Chast II).

Ivanova, N. (1989). Rolyata na Yuzhnoslavyanskiya „İliriuski” Ezik v Bllgaro-Khırvatskite Knizhovnoezikovi Kontakti Prez XVII. - V: Vtori Mezhdunaroden Kongres Po Bulgaristika. Dokladi Sravnitelno i Stpostavitelno Ezikoznanie, Sofiya, 305-313.

Ivanova, N. (1997a). Smesenite Knizhovnoezikovi Tipove i Barokıt. Bılgarskata Raznovidnost Na Yuzhnoslavyanskiya "İliriusski" Ezik Prez XVII - XVIII v. (I). - V: Sipostavitelno Ezikoznanie. XXII, 3 , s. 100-129.

Ivanova, N. (1997b). Smesenite Knizhovnoezikovi Tipove i Barokıt. Bılgarskata Raznovidnost Na Yuzhnoslavyanskiya "İliriŭski" Ezik Prez XVII-XVIII v. (II). - V: Sipostavitelno Ezikoznanie. XXII, 4 , s. 53-84.

Ivanova, N. (1998). Kontaktni Sinonimi v Sichineniyata na Petır Bogdan Bakshich, Filip Stanislavov i Krıst'o Peǐkich. - V: Starobılgaristika. - XXII, 4, s. 101-110.. A 16760162.

Ivanova, N. (1999b). Abagar (1651) na Filip Stanislavov v yuzhnoslavyanski kontekst. - V: Starobilgarska literatura. - 31, s. 120-126. 
Ivanova, N. (1999a). Sırbi İ Bılgari Mezhdu Srednovekovieto İ Novoto Vreme - Ezikovi İzmereniya Na İstoricheskoto Siznanie. - V: Stpostavitelno Ezikoznanie. - XXIV, 2-3, s. 72-80.

İstoriya(1962).Istoriya na bilgarskata literatura. T. 1. Starobılgarska literatura, S., 402-409

Jerkov, J. (1979). , Parčevič et Stanislavov: Formes et caractères d'une literature militante. - In: Ricerche Slavistiche, vol. XXIV-XXVI, 157-178.

Jerkov, J. (1985). Sulla sorte dei manoscritti dei Pauliciani bulgari. - "Europa Orientalis" 4 : 29-37.

Leontik, M. (2016). Poteklo, Adaptacija i Semantika na Turskiot sufiks-di/-ti/-DI/(-dı,-di,-du,-dü,-tı,-ti,-tu, tü) vo Makedonskiot jazik. Godițen zbornik 2016-Filoloṭki fakultet, UGD-Ṭtip, 8, 27-36.

Stanchev, K. (1975). Poeziyata na bılgarskite pavlikyani. - V: Literaturna misıl, 1, s. 63-71.

Stanchev, K. (1981). Literaturata na blgarite katolitsi prez XVII i XVIII vek i prekhodit ot Srednovekovie kım Vızrazhdane. - V: Literaturna misıl, kn. 3, Sofiya, 3-11.

Stanchev, K. (1988). Poeziyata na bılgarite katolitsi prez XVIII-XIX vek i viprosit za neŭnite obraztsi. $\mathrm{V}$ : Bulgariya, Italiya $i$ balkanite. Obshtestveno-istoricheski $i$ kulturno-esteticheski vzaimootnosheniya XV-XX v., S. s. 155-159.

Stanchev, K. (1995). Otets Eduardo ot Torino i bilgarskata pavlikyanska knizhnina. - V: Dokladi ot Petiya Bllgaro-italianski simpozium, Piza, 24-28, 169-181.

Stanchev, K. (1998). Nyakoi utochneniya otnosno istoriogeografskite sichineniya na Petır Bogdan Bakshich - Paleobulgarica, 22, № 2, 128-132.

Starobılgarska Literatura (2003). Starobılgarska Literatura. Entsiklopedichen Rechnik, Veliko Tirnovo.

Tsibranska-Kostova, M., M. Abadzhieva (2016) . Za leksikata s chuzhd proizkhod v katolicheskata knizhnina ot XVII-XVIII vek /po material na Abagara na Filip Stanislavov i sbornik № 778 NBKM na Petŭr Kovachev Tsarski/. - Izvestiya na Instituta za bŭlgarski ezik „Prof. Lyubomir Andreĭchin“, kn. XXIX, s. 7 - 47. ISSN 0323-9934.

Tsonev, B. (1923). Opis na slavyanskite rrkopisi v Sofiǔskata narodna biblioteka, tom II, S.

Tsonev, B. (1923). Opis na Slavyanskite Rıkopisi v Sofiyskata Narodna Biblioteka, Tom II, S.

Walczak-Mikołajczakowa, M. ( 2004). Pismiennictwo katolickie w Butgarii, Poznan.

Yenisoy, Hayriye (2007). Balkanlar El Kitabı. Dil ve Edebiyat, Cilt III, Karam \& Vadi, 171-190. 